\title{
Enhancement of the radiation monitoring and emergency response system in the Murmansk region
}

\author{
L.P. Amozova ${ }^{2}$, R.V. Arutyunyan ${ }^{1}$, S.A. Bogatov ${ }^{1}$, L.A. Bolshov ${ }^{1}$, \\ S.L Gavrilov ${ }^{1}$, S.N. Druzhininsky ${ }^{2}$, V.P. Kiselev ${ }^{1}$, K.V. Ogar ${ }^{1}$, \\ I.A. Ossipiants ${ }^{1}$ and V.A. Khandobin ${ }^{3}$ \\ ${ }^{1}$ Nuclear Safety Institute of Russian Academy of Sciences,115191, 52, B.Tulskaya, \\ Moscow, Russia \\ ${ }^{2}$ Murmansk Regional Government, 183006, 75, Lenin, Murmansk, Russia \\ ${ }^{3}$ FSUE "Servo", 183017, 100, Lob ova, Murmansk, Russia
}

\begin{abstract}
The emergency response and radiation monitoring system in the Murmansk region established by request of the Murmansk region Government was developed by the Energy Safety Analysis Center of Nuclear Safety Institute of the Russian Academy of Sciences (IBRAE RAS) in 2005-2007 under a special project. The system meets all actual international and domestic requirements and may be used as a prototype in similar projects.
\end{abstract}

\section{INTRODUCTION}

Large scale activities aimed at decommissioning of a large number of radiation-hazardous facilities of the Navy are being implemented in the North-West Region of Russia throughout the last decade. An important part of these activities is nuclear, radiation, and environmental safety assurance. One of the key elements of the system for safe decommissioning of radiation-hazardous facilities is preparedness to response to possible radiological accidents. Therefore, a modern response system in the Murmansk Region is a necessary factor ensuring protection of population and territories in case of radiological accidents at facilities involved in nuclear submarine decommissioning, spent nuclear fuel and radioactive waste management.

The Project of development of radiation monitoring and emergency response system in the Murmansk Region was included in the top priority projects according to the Strategic Master-Plan for decommissioning of NS and other radiation-hazardous facilities of the North-West Region of Russia, which was developed on the behalf of the "Northern Dimension Environmental Partnership Fund". The Employer of the works is the Government of the Murmansk Region. The project is implemented by the Energy Safety Analysis Centre of IBRAE RAN. The main objective of the Project is overall enhancement of the system for radiation monitoring and emergency response to potential accidents at radiation-hazardous facilities involved in NS decommissioning and management of SNF and RW in the Murmansk Region.

The Project is aimed at enhancing the preparedness of the emergency response forces, minimization of the consequences of possible radiological accidents, increasing the effectiveness and efficiency of decision-making and realization of population and environment protection measures.

The main directions of activities:

- Modernization of the existing and creating automated radiation monitoring systems (ARMS) for facilities and territories, including mobile radiation surveillance laboratories;

- Establishment of the Regional Crisis Centre (RCC) of the Murmansk Region and the Crisis Centre of FSUE “SevRAO” (CC of FSUE “SevRAO”);

- Setting up communication systems for transfer, acquisition, processing, storage and presentation of data for participants of emergency response at the facility, regional and federal levels; 
- Development of software and hardware systems for expert support of decision-making on personnel, population and environment protection activities;

- Establishment of a system for expert support of the RCC of the Murmansk Region and CC of FSUE "SevRAO" by Technical Crisis Centre of IBRAE RAN.

The implementation of the Project will provide Murmansk Region with an up-to-date systems of radiation monitoring, informational, analytical and real-time expert support of executive authorities in planning and implementation of adequate protection measures in case of radiation accidents. Functional diagram of emergency response system of the Murmansk Region is shown on Figure 1.

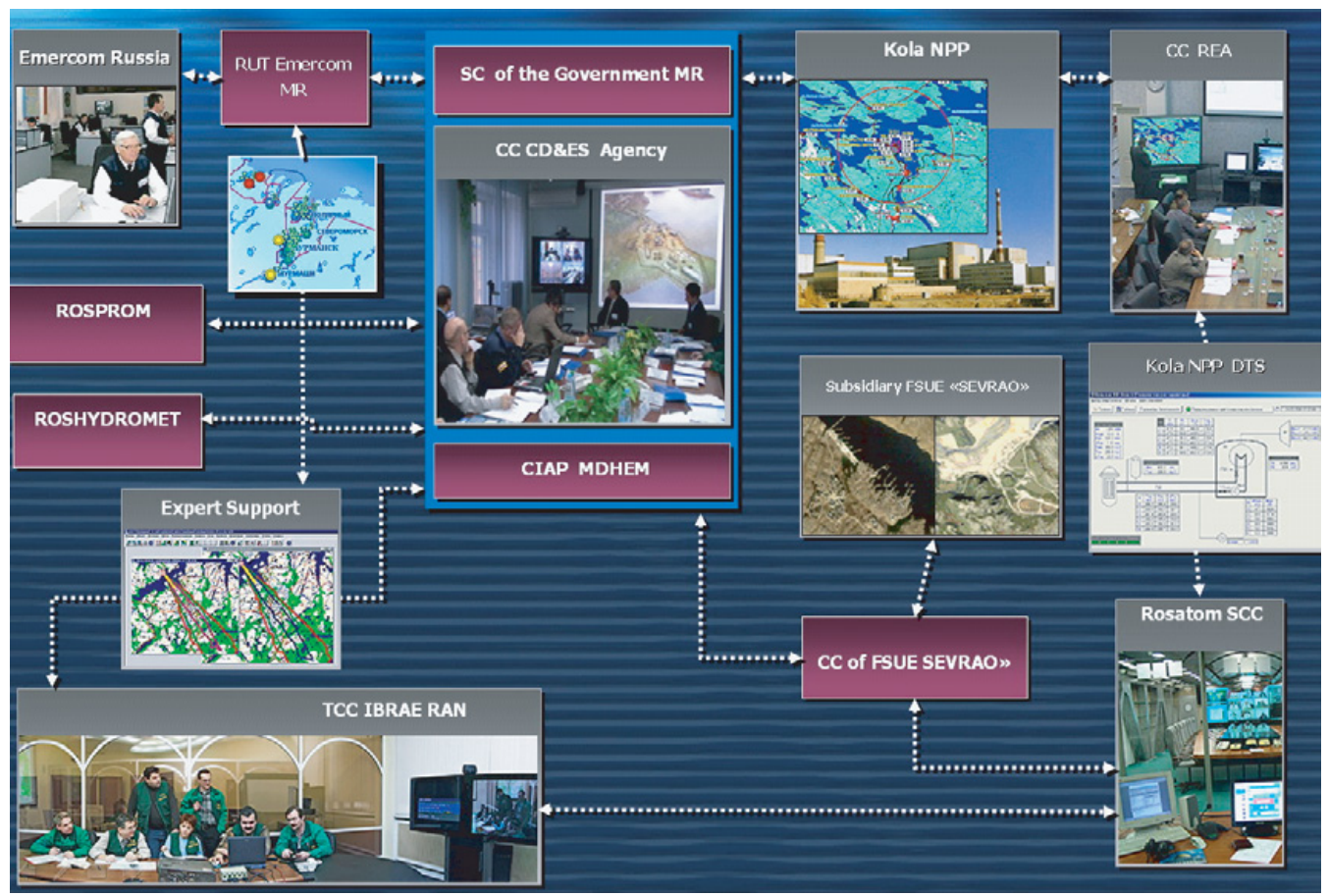

Figure 1. Functional diagram of emergency response system of the Murmansk Region.

\section{REGIONAL CRISIS CENTRE OF THE MURMANSK REGION (RCC)}

Regional Crisis Centre (RCC) was established to provide informational and technical support for decision-making on protection of population and territories in case of emergency situations at nuclear and radiation-hazardous facilities. Everyday activities of RCC include on-line monitoring of the radiation situation in the territory of the region, planning and verification of actions aimed at prevention of ES in the territory of the region.

RCC includes three elements: the Situation Crisis Centre (SCC) of the Government of the Murmansk Region, Crisis Centre of the State Regional (Murmansk) Agency for Civil Defense, Emergency Situations and Fire Safety (SRA CD\&ES) and the Centre of Information Acquisition and Processing of Murmansk Department for Hydrometeorology and Environment Monitoring (MDHEM).

Main tasks of RCC:

- informational and technical support of the administration of the region and administrative agencies in decision-making on mitigation of the consequences of radiation accidents;

- planning and verification of emergency response activities in the region; 
- real-time monitoring of the main parameters of radiation situation in the territory of the region;

- provision of interaction between the participants of emergency response at local regional and federal levels;

- Informational, methodological and technical support of measures aimed at provision of emergency preparedness of the emergency response forces in the Murmansk Region.

Information systems and software of the facilities are required for decision-making on protection measures for the personnel, population, and territories in case of a radiation Emergency Situation.

This software includes data bases, informational and geoinformational systems, simulation systems, computer manuals and engineering programs providing assessment and forecast of the consequences of radiation accidents, as well as systems providing access to reference and on-line information; geoinformational systems containing maps and reference information about the region, and territories of location of radiation-hazardous facilities, simulation systems includes systems for express assessment of the radiation situation; computer systems for assessment and forecast of spreading of radio nuclides in atmosphere and water; systems for assessment and forecast of contamination of territories and environment; systems for assessment of population exposure doses, computer manuals and engineering programs for assessment of radiation.

A specific set of software and informational resources is used at the crisis centers depending on the functions of the centre. The software installed at the Centre of Information Acquisition and Processing of MDHEM provides on-line processing of the data of radiation monitoring and forecasting of atmospheric and water transboundary transport of radioactivity. The software systems of CC of Agency of CD\&ES and FS provide support of decision-making on protection of population and territories.

\section{CRISIS CENTRE OF FSUE "SEVRAO"}

FSUE "Northern Federal Facility for Radioactive Waste Management" (FSUE "SevRAO") was established to provide infrastructure for NS decommissioning management of radioactive waste and spent nuclear fuel, and remediation of radiation-hazardous facilities in the north of Russia. The facility controls three subsidiaries - the former naval coastal maintenance bases in Andreeva Bay and in Gremikha, and reactor compartment long-term storage facility in Saida Bay.

Crisis Centre of FSUE "SevRAO" is located at the administration of the facility in Murmansk and includes:

- software - data bases and informational reference systems providing information on the condition of the radiation hazardous facilities and works on NS decommissioning, scenarios of possible accidents, plans for protection of population and territories, library of electronic maps, calculation and simulation software - express system for forecasting of radiological situation in case of atmospheric releases of radioactivity, engineering applied programs for assessment of exposure doses and contamination, software for display of radiation monitoring data;

- hardware - videoconferencing equipment, audio and video presentation equipment, modern operator workstations, server and communication equipment, uninterrupted power supply system;

- communications - facility telephone network, automatic notification system, fiber optic lines for communication with the RCC of the Murmansk Region, connection to the satellite data transfer system of Rosatom, reserve communication lines;

\section{DEVELOPMENT OF THE MURMANSK TERRITORIAL AND SITES ARMS}

Murmansk territorial ARMS provide on-line information about the radiation situation in the Murmansk Region, and provide information for regional and federal authorities, and for the population. MDHEM was appointed as the centre for acquisition, storage and primary analysis of monitoring information by the corresponding legal acts. 
Works in the framework of the Project: installation of 23 automated stations for gamma-radiation dose rate monitoring in the territory of the region; installation of 9 automatic weather stations; installation of modern computer and communication equipment at MDHEM and at the local data acquisition centers of ZATO; development of the new and updating of the existing software of the system; integration of the two sensors at the boundary of FSUE "Atom lot" site into the system.

Since 1995, "Nepal" shipyard has been involved in scrapping of nuclear-powered naval ships. The site radiation monitoring system is being created to control the radiation situation at FSUE "Nepal" SY to ensure timely personnel protection in emergency in the areas of radiation hazardous activity conduct.

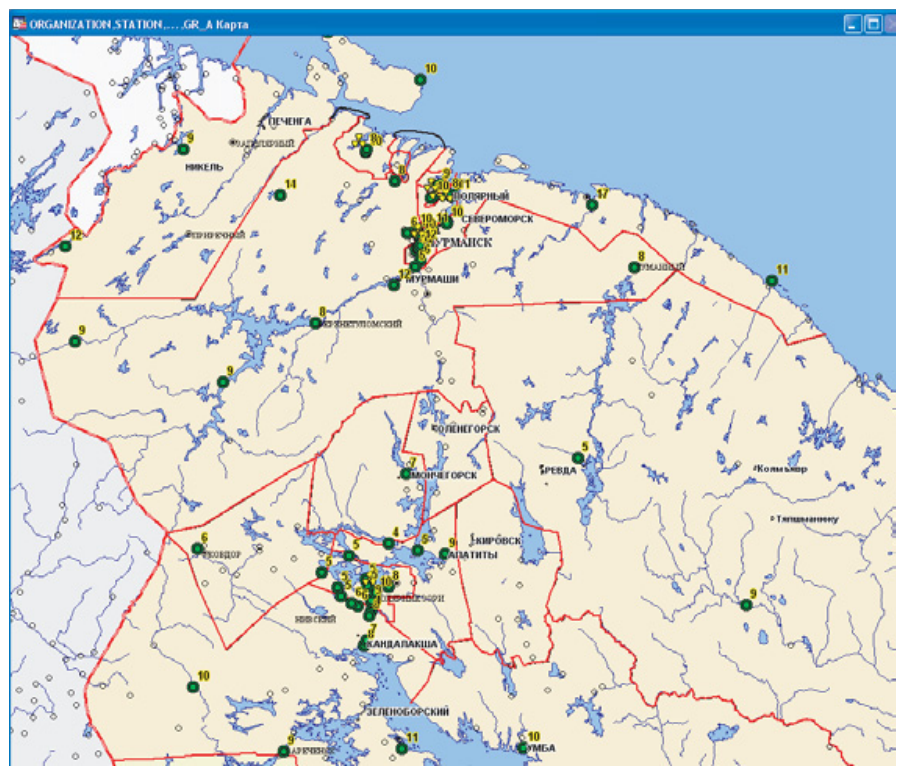

Figure 2. Location of monitoring stations of the Murmansk Regional Radiation Monitoring System.

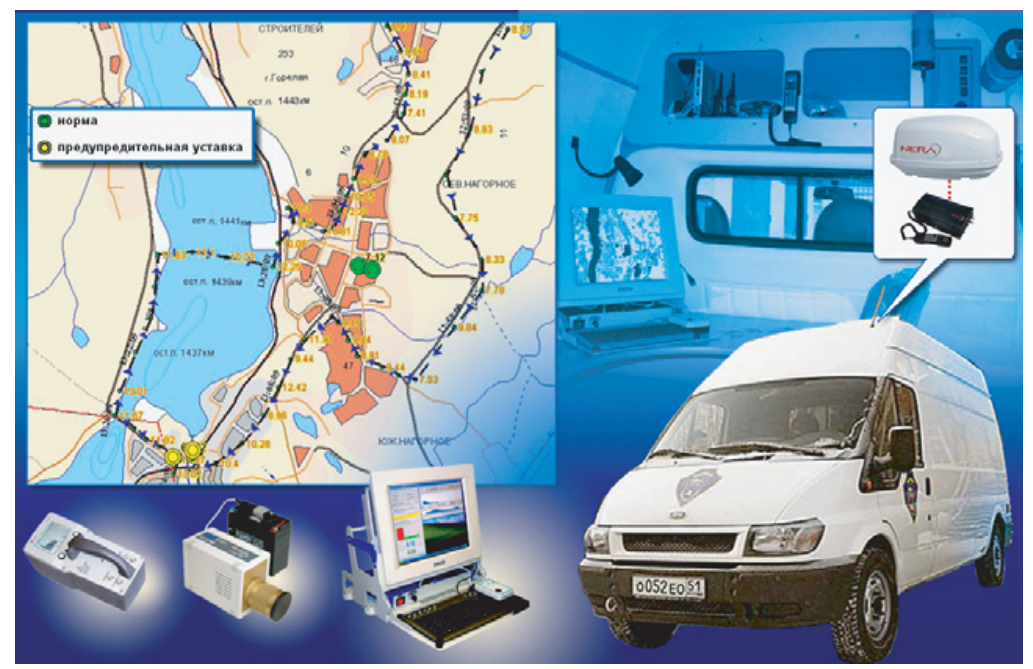

Figure 3. Mobile Radiation Laboratory( MRL). A fragment of data transferred from MRL. 


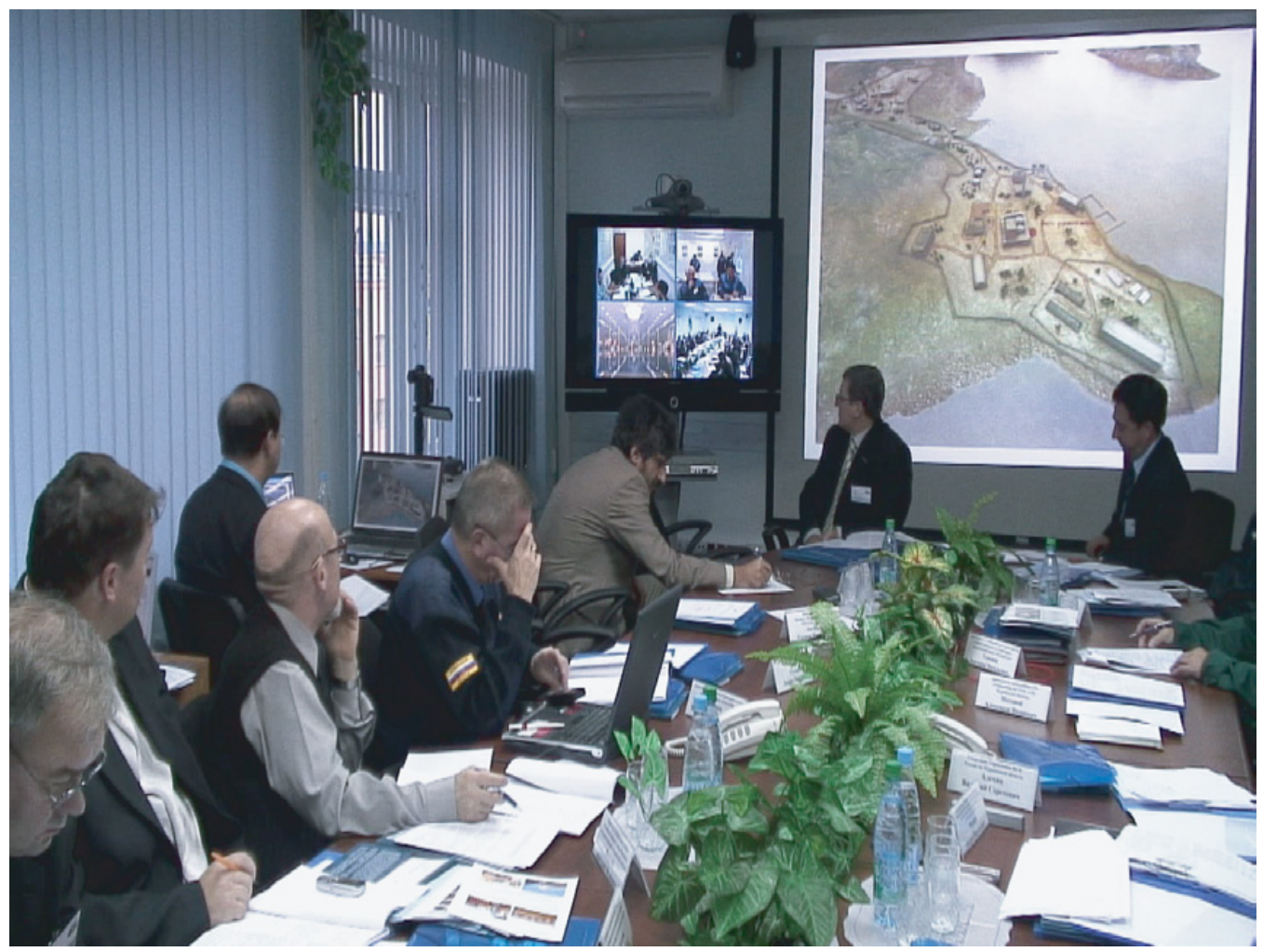

Figure 4. Emergency State Commission at work during the exercise.

25 gamma-radiation dose rate sensors of the Kola NPP ARMS are located in the 30-km control area. The measurement data are transmitted on-line to the Crisis Centre of "Rosenergoatom" Concern, SCC of Rosatom and TCC of IBRAE RAN. On the Concern's "Rosenergoatom" initiative, the ARMS of the Kola NPP surveillance area were integrated into the regional ARMS. This work is implemented separately from the Project.

\section{MOBILE RADIATION SURVEILLANCE LABORATORIES (MRL)}

Four mobile radiation surveillance laboratories (MRL) are designed for operative radiation surveillance duties in case of radiological emergencies.

Capabilities: detection and localization of radioactivity sources and contamination; sampling and express-analysis of soil, air and water samples; determination of the characteristics of contamination; mapping of the boundaries of contaminated areas;

Transmission of measurement data to crisis centers in a real-time mode.

MRL equipment includes: measurement equipment - stationary and portable gamma-spectrometer installations, dosimeters, alpha-, beta-, and gamma-radiometers, sampling equipment; computer and communication equipment - Inmarsat satellite terminal, cellular telephone communications, VHF radio station, GPS satellite navigation system, industrial computer and an auxiliary laptop, photo and video equipment; specialized software; auxiliary equipment - vehicle power supply system, including petrol generator, and adaptation of the equipment to climatic conditions; working clothes and deactivation equipment. 
Two mobile laboratories are supplied to FSUE "SevRAO" and two more to the Murmansk Agency of CD\&ES and FS.

\section{TECHNICAL CRISIS CENTRE IBRAE RAN (TCC IBRAE RAN)}

TCC IBRAE RAN carries out scientific, technical, and expert support of the Situation Crisis Centre of Rosatom, Centre for Crisis Situations Management of EMERCOM of Russia (CCSM of EMERCOM), Crisis Centre of "Rosenergoatom" Concern (CC of Rosenergoatom Concern), Information and Analytical Centre of Rostehnadzor (IAC of Rostehnadzor), facilities, and local agencies for prevention and mitigation of ES.

Main functions of TCC in the framework of the Project: expert support of the personnel of crisis centers and development of recommendations on minimization of the consequences of radiological ES for personnel, population and territories of the region; scientific, methodical, and technical support of actions aimed at assuring preparedness of emergency response forces, including participation in exercises and training; scientific, informational, methodical and technical support of design, development, and introduction of new software and hardware for support of decision-making on protection of personnel, population and territories.

\section{CONCLUSIONS}

In October 2007, during the Zapolyarye-2007 exercise, interface between all elements of the Murmansk region emergency response system and the Murmansk Regional Division of the United National Emergency Prevention and Response System was tried out in practice. The results of the exercise were highly commended by the Murmansk region authorities. An IAEA mission, while assessing the emergency-response status in the Murmansk region, confirmed a high level of preparedness and recommended the system established for further expansion. 